\title{
De pessoa a pessoa passando pela doença
}

\author{
A personal approach, beyond disease
}

\section{De persona a persona, pasando por la enfermedad}

Gustavo Diniz Ferreira Gusso. Universidade de São Paulo (USP). São Paulo, SP, Brasil. gustavo.gusso@usp.br (Autor correspondente)

Paulo Poli Neto. Universidade Federal do Paraná (UFPR). Curitiba, PR, Brasil. ppolineto@gmail.com

A atual edição da Revista Brasileira de Medicina de Família e Comunidade (RBMFC) traz uma variedade de artigos bastante representativa da atuação dos profissionais que fazem a Atenção Primária à Saúde (APS) no dia a dia. E a RBMFC deseja ser cada vez mais um instrumento de divulgação de conhecimentos adquiridos na linha de frente.

Os dois casos clínicos lidam com temas bastante caros a atuação do médico de família e comunidade. $\mathrm{O}$ artigo de herpes zoster trata de um problema frequente na prática mas cuja apresentação não foi típica. Muitas vezes escutamos nos bancos da faculdade que a apresentação da doença foi "típica" ou "de livro". Mas aprendemos na Medicina de Família e Comunidade (MFC) que cada pessoa é única e que os problemas de saúde aparecem de diferentes maneiras em cada pessoa. Isso faz da pratica na APS complexa e carregada de incertezas. Se por um lado vemos problemas que se repetem, por outro lidamos com pessoas e seus problemas únicos. Talvez não seja possível entender exatamente porque um adolescente saudável teve um herpes zoster extenso. A solução para essa incerteza não é tampouco procurar exaustivamente e às vezes até de forma constrangedora por alguma imunodeficiência. O segundo caso clinico trata de outro tema crucial na prática diária: efeito colateral de medicamento. A quantidade de medicamentos usada sem um motivo que justifique faz com que aumente a chance de que o risco seja maior que o benefício. Portanto, é mandatório que o profissional, em especial o médico, trabalhe com alguma ferramenta de pesquisa de efeito colateral a tiracolo como o Epocrates, o British National Formulary (BNF) ou mesmo o Medscape. Por causa da elevada incidência, descartar efeito colateral deve ser intrínseco a qualquer consulta. Efeitos colaterais que são também sintomas frequentes como náusea, tontura e diarreia dificultam a abordagem e fazem com que muitos profissionais "neguem" o tema. Essa negação pode custar o diagnóstico de um efeito colateral mais raro e específico como a osteonecrose mandibular em pacientes que fazem uso de medicamentos bifosfonados. 
Alguns artigos tratam de ferramentas do MFC como prevenção quaternária e o registro clinico. A forma de registro mais consagrada na Atenção Primária tem sido o Prontuário Médico Orientado por Problemas (PMOP) e seu consequente método SOAP. ${ }^{1}$ Há muita controvérsia da quantidade de dados que devem ser estruturados e a quantidade que deve ser em texto livre. O artigo aborda essa dicotomia através de um estudo transversal de 318 consultas. Se por um lado os dados estruturados via, por exemplo, Classificação Internacional de Atenção Primária (CIAP), ${ }^{2}$ ajudam na avaliação da qualidade da atenção e no cálculo da probabilidade pré-teste, por outro tomam tempo que poderia ser usado para descrição de texto livre, que segundo o autor, ajuda na compreensão do que de fato se fez na consulta. É a constante busca da informação na forma certa e na medida certa, nem pouca nem muita. Qual será o erro mais frequente? Informação de menos ou informação em excesso e desnecessária? Ou o que é considerado um registro adequado? O caminho é voltar a investir no texto livre e em mecanismos que consigam classificar e estruturar o texto? Por enquanto não há aparentemente grandes respostas e resultados nesse campo. Os dados estruturais continuam sendo importantes para analises futuras com todas as limitações apontadas.

Por fim, a prevenção quaternária que tem sido uma ferramenta bastante estudada no Brasil e no mundo é tratada no artigo que usa o auto-exame da mama e dos testículos como exemplo. Tem sido frequente movimentos que tentam fazer com que a saúde do homem siga o mesmo caminho desastroso que seguiu a saúde da mulher com excessos de intervenções médicas. Não bastasse o fracasso da reposição hormonal feminina para alertar os médicos e a população, há um intenso movimento de marketing pela "reposição de testosterona". Algo similar se passou com outros rastreamentos sobre os quais talvez se possa traçar algum paralelo como câncer de colo de útero/câncer de pênis e auto exame da mama/auto exame dos testículos. Em geral os rastreamentos femininos têm levado "vantagem científica" o que fortalece a cultura do homem não procurar o médico e a retroalimentação da necessidade de "rastreamentos" como se a única causa de morte precoce fosse "a falta de rastreamento e a pouca ida ao médico". Nesse contexto as condições sociais, as relações familiares, o estresse, a relação com o trabalho, a dieta, e todos os determinantes sociais de saúde são meros "detalhes".

Desta forma, a prevenção quaternária, entendida como ferramenta de pesquisa e ação, está relacionada ao sobrediagnóstico na medida que ambos procuram evitar intervenções que causem mais danos do que benefícios. No último congresso que tratou especificamente de sobrediagnóstico, ${ }^{3}$ alguns pesquisadores fizeram com que acendesse uma luz amarela. Muitos cientistas estão procurando, através de testes genéticos, estratificar ou personalizar o tratamento. Ou seja, hoje só se sabe estatisticamente e retroativamente a quantidade de sobrediagnósticos produzida por determinados rastreamentos. Estes cientistas esperam resolver o empecilho com testes genéticos. Assim, desejam que no futuro próximo não haja câncer de mama mas "o câncer de mama da Senhora X cujo tratamento é o medicamento Y". Enfim, alguns nomes que tem sido usados nessa reinvenção da pesquisa clínica são "medicina estratificada" e "medicina personalizada". ${ }^{4}$ Esta estratégia dificulta a realização de ensaios clínicos randomizados já que "cada pessoa tem um câncer diferente". É a distorção de um dos mais importantes princípios da medicina de família e comunidade: entender que pessoa tem a doença é diferente de entender que genoma a pessoa com a doença tem. 


\section{Referências}

1. Weed LL. Medical records that guide and teach. N Engl J Med. 1968;278:593-600, 652-7. DOI: http://dx.doi.org/10.1056/ NEJM196803142781105

2. World Organization of National Colleges, Academies, and Academic Associations of General Practitioners/Family Physicians Classificação Internacional de Atenção Primária (CIAP 2)/Elaborada pelo Comitê Internacional de Classificação da WONCA (Associações Associations of General Practitioners/Family Physicians Classificação Internacional de Atenção Primária (CIAP 2)/Elaborada pelo Comitê Internacional de Classificação da WONCA (Associações Nacionais, Academias e Associações Acadêmicas de Clínicos Gerais/Médicos de Família, mais conhecida como Organização Mundial de Médicos de Família); Consultoria, supervisão e revisão técnica desta edição, Gustavo Diniz Ferreira Gusso. - 2. ed. - Florianópolis : Sociedade Brasileira de Medicina de Família e Comunidade, 2009.

3. Preventing Overdiagnosis [home page on the Internet]. BMJ. [Acesso em 24 de Sep de 2015]. Disponível em http://www. preventingoverdiagnosis.net/

4. Realising the potential of stratified medicine [home page on the Internet]. Academy of Medical Sciences. [Acesso em 24 de Sep de 2015]. Disponível em https://www.acmedsci.ac.uk/viewFile/51e915f9f09fb.pdf 